\title{
Nanotechnology for 5G
}

\author{
Ahmed Farahat Mohamed ${ }^{1}$, Dr. Amin Babiker A/Nabi Mustafa ${ }^{2}$ \\ ${ }^{1,2}$ Department of Telecommunication, Faculty of Engineering, Al Neelain University, Khartoum, Sudan, 2016
}

\begin{abstract}
The 5G technology which is expected to be launched by 2020 it is an upgraded version of the existing and establishing network 4G known as LTE (Long Term Evolution) network, this technology started an era of highly-efficient information society. It is expected that the wireless technologies will become wider and deeper in the coming years. The main contribution of this paper is definition of $5 G$ i.e. Fifth Generation mobile network concept which will be technically touching the real Heights and also covers technologies like Nanotechnology, Cloud Computing, Flat IP concept, BDMA and more.
\end{abstract}

Keywords: BDMA, Nanotechnology, Cloud Computing

\section{Introduction}

5G will be the one which will change the face of the mobile communication the Major distinguishing features of $5 \mathrm{G}$ are wide network availability with the high throughput which basically works on the packet switched wireless system. OFDMA will be the salient feature which will be used in $5 \mathrm{G}$ so as to achieve the high speed data transfer touching the rate of around $1 \mathrm{Gbps}$ also another feature that can be envisaged is the emergence of a network which is capable of supporting World Wide Wireless Web (wwww) which is expected by 2020. Technology which will be used in the $5 \mathrm{G}$ network is the most powerful as well as demanding also the challenging part will be the integration of the wide range of technologies into a small device. High Resolution is the main feature offered by $5 \mathrm{G}$ for the high end users. Bidirectional huge bandwidth is another milestone to be achieved by the upcoming technology [1]. Error free transmission will be ensured due to the policy based Quality of Service. Unequalled steadiness is guaranteed by the transporter type gateway. Sustainability can be figured out up to 60,000 connections and can be counted more as expected.

The paper has been organized according to the following sections: Section-1 is the introduction to the research. Section-2 consists of $5 \mathrm{G}$ wireless communication system. Section-3 Nanotechnology. Section-4 contains cloud computing. Section-5 all IP Network. Section-6 contains BDMA. Section-7 contains comparison between $5 \mathrm{G}$ and $4 \mathrm{G}$. Section-8 conclusion followed by references.

\section{5G wireless communication system}

The $5 \mathrm{G}$ wireless communication system will be a converged system with multiple radio access technologies integrated together. $5 \mathrm{G}$ can support a wide range of applications and services to comprehensively satisfy the requirements of the information society by the year 2020 and beyond. 5G networks use the flat IP concept also $5 \mathrm{G}$ uses Nanotechnology as a defensive tool for security concern that arises due to the flat IP. Surely the Flat IP network is the key to make $5 \mathrm{G}$ acceptable for all kind of technologies.

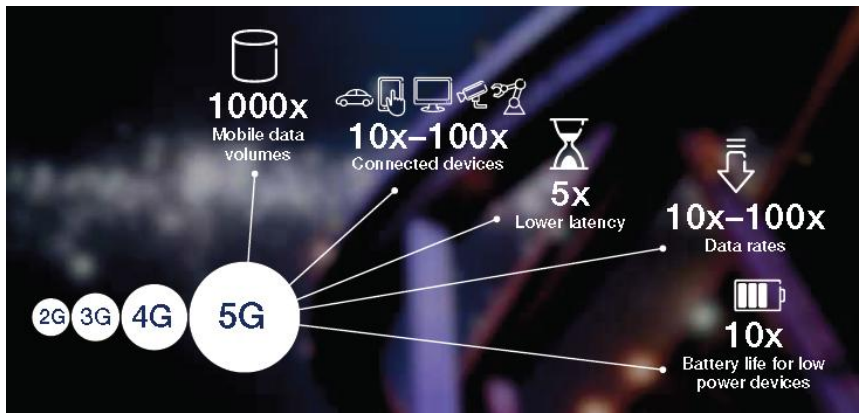

Figure 1: Applications supported by $5 \mathrm{G}$

The main advantage of Flat IP is that it provides a new way to identify devices using the symbolic names unlike the hierarchical architecture method that has been used by the normal IP address; this will help wireless operators in many ways as given below:

- Lower costs.

- Reduced system latency.

- Decoupled radio access and core network evolution.

- Reduce the number of network elements in the data path to lower operations costs and capital expenditure.

- Partially decouple the cost of delivering service from the volume of data transmitted to align infrastructure capabilities with emerging application requirements.

- Minimize system latency and enable applications with a lower tolerance for delay; upcoming latency enhancements on the radio link can also be fully realized.

- Evolve radio access and packet core networks independently of each other to a greater extent than in the past, creating greater flexibility in network planning and deployment.

- Develop a flexible core network that can serve as the basis for service innovation across both mobile and generic IP access networks.

- Create a platform that will enable mobile broadband operators to be competitive, from a price/performance perspective, with wired network.

The 5G Nancore is a convergence of below mention echnologies. These technologies have their own impact on exiting wireless network which makes them in to $5 \mathrm{G}$.

- Nanotechnology.

- Cloud Computing.

- All IP Platform. 


\section{International Journal of Science and Research (IJSR) \\ ISSN (Online): 2319-7064}

Index Copernicus Value (2013): 6.14 | Impact Factor (2014): 5.611

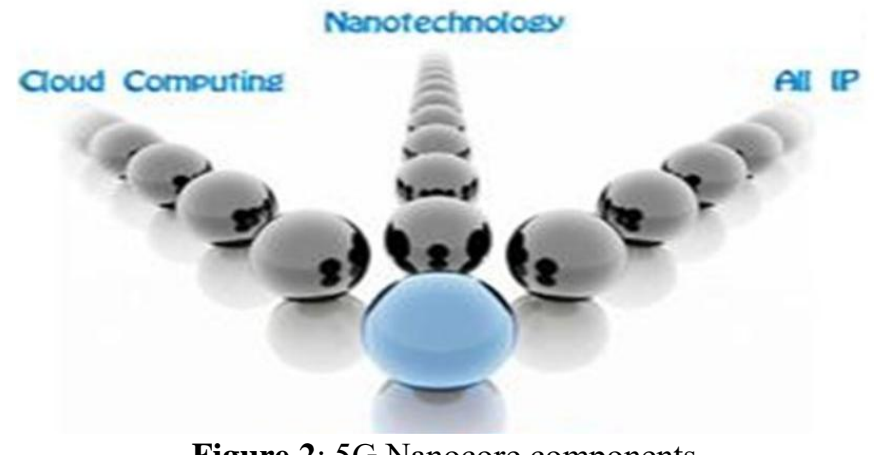

Figure 2: 5G Nanocore components

\section{Nanotechnology}

This is the application of nano science to make the control process to a nano meter scale which will be in between 0.1 and $100 \mathrm{~nm}$. This particular field is known as Molecular Nano Technology (MNT) [2]. Atom by atom and molecule by molecule based control of the structure of matter. The telecommunication industry will radically get changed into the latest Nanotechnology in little year time. Putting the impact in both mobile as well as core network is the mode of operation of the nanotechnology. Perfection in security and the better impact on the sensor makes the nanotechnology the most significant in its row. The most common and general identity of a human being nowadays is the mobile device. The nano equipment in the $5 \mathrm{G}$ nano core is the mobile phone itself as they are geared up with the nanotechnology. Wireless industry mainly aims at the implementation of the intelligence which will ensure that the computation and communication are available as desired. The introduction of intelligence in the mobile devices will help in embedding the devices in the human environments that can create a new platform which will enable the ubiquitous sensing, computing and communication. The nano equipments will be loaded with some of the core features like self-cleaning, selfpowered, sensible to the environment with which it is been interacting, flexible and also transparent.

Introduction of the Graphene's transistor is the milestone to be achieved [3]. A transistor which is been built using the new material by name Graphene, mainly consists of a form of graphite that consists of a single layer of carbon atoms which has been arranged in the form of honeycomb pattern. The particular structure will help the electrons to travel through it very quickly and gives greater efficiency than the commonly existing transceiver chip material. The latest achieved frequency by the Graphene's transistor is $26 \mathrm{GHz}$ which is miles away from the current technology standards. Frequencies above $1 \mathrm{THz}$ are been used for the military for seeing the concealed weapons and medical uses for imaging without using harmful x-rays. At conventional frequencies, transceivers based on grapheme will be able to make both the cell phone and base stations more sensitive for the betterment in picking weak signals. The main challenge is to distinguish the radio signals from the other waves around it. A more sensitive mobile device with a better signal to noise ratio will be able to take better advantage of the signal available from the nearest cell tower.
Cell phones enhanced with the carbon nanotube will be introduced soon which comes under the nanotechnology. In 5G Nanocore these mobile are referred as NanoEquipment as they are geared up with nanotechnology. One of the central visions of the wireless industry aims at ambient intelligence: computation and communication always available and ready to serve the user in an intelligent way. This requires that the devices are mobile. Mobile devices together with the intelligence that will be embedded in human environments home, office, public places, will create a new platform that enables ubiquitous sensing, computing, and communication Specs of Nano Equipments given as follow:

- Self Cleaning - the phone cleans by itself

- Self powered - the phone derives its energy/power from the sun, water, or air.

- Sense the environment - the phone will tell you the weather, the amount of air pollution present, etc.

- Flexible - bend but not break

\section{Cloud Computing}

Technology used for maintaining data and applications that uses the internet and central remote server is known as Cloud Computing. In $5 \mathrm{G}$, the central remote server will be the main provider of content. Clouding will introduce a layer in which the consumers can use the applications without installation and also personal files can be accessed with the use of internet access. In Nanocore the same concept will be used in which the user tries to access his private account from a global content provider in the form of cloud. $5 \mathrm{G}$ will add on the real time applications through the Nanocore clouding.

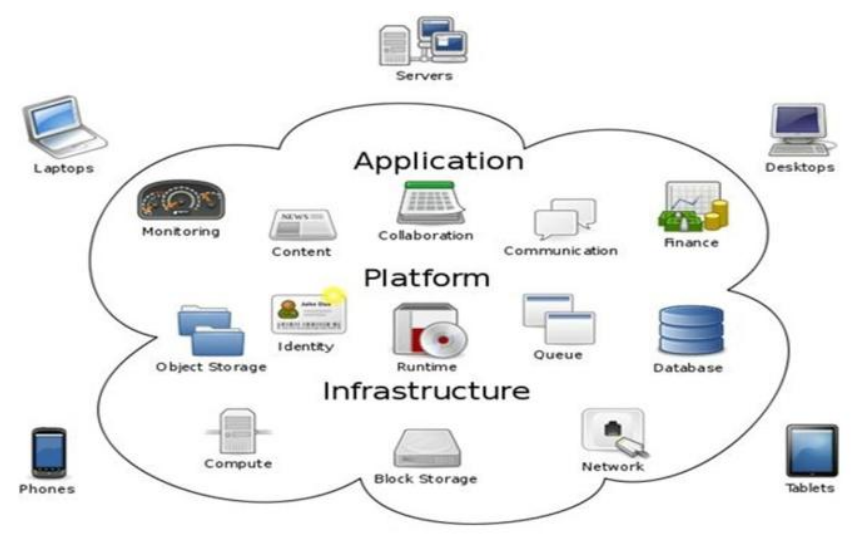

Figure 3: Segments of Cloud Computing

The Cloud computing has three segments as follows:

- Applications

- Platform

- Infrastructure

Applications means, software services on demand. The products which are used to deploy internet is generally referred to as the platform segment of cloud computing. The infrastructure and is the backbone of the entire concept. The infrastructure vendors will allow the user to build applications in this platform. Satisfying the customer demand is attained in $5 \mathrm{G}$ by the mutual integration of all the three segments. The CAPEX (Capital Expenditure) of $5 \mathrm{G}$ has been reduced by the cloud computing deployment. 


\section{International Journal of Science and Research (IJSR) \\ ISSN (Online): 2319-7064}

Index Copernicus Value (2013): 6.14 | Impact Factor (2014): 5.611

\section{All IP Network}

A common platform is required to interact for the convergence of different technologies to form a single $5 \mathrm{G}$ Nanocore. The essential part of the $5 \mathrm{G}$ network will be the Flat IP architecture. So as to meet the increasing requirement of the mobile telecommunication market, All IP Network (AIPN) has been introduced by the $3 \mathrm{GPP}$ system. Migrating into AIPN will meet the requirements of the customer for the real time data applications delivered over the mobile broadband networks. Provision of the complete edge performance in terms of both performance and costs is the primary focus of the enhanced packet switched technology. The touched benefits of the IP architectures are reduction of the system latency, improved user experience, globally seamless access, core network evolution, and decoupled radio access, cost effectiveness and much more. Placement of the stringent performance demands on IP based equipments and devices, which leads to the growing demand of the multicore technology. Strong demands have been seen in the Next Generation Network (NGN) infrastructures both in wired and wireless layers.

Another important challenge in the telecommunication field is that the network should be in such a way that it should be flexible and improved to provide larger number of connections to multiple users without losing the quality within the limited frequency spectrum available with the increased system capacity. Communication made possible within limited spectrum and time is the biggest challenge to be tackled properly without any loop holes. Meeting this target is achieved by the implementation of multiple access techniques like OFDMA, FDMA, TDMA, CDMA, etc. OFDMA (Orthogonal Frequency Division Multiple Access) technique divides and allocates the available frequency resources to maximize the resource utility efficiency. In OFDMA, the multiuser capability is achieved by assigning each user a subset of OFDM (Orthogonal Frequency Division Multiplexing) subcarriers. OFDM is a digital transmission technique that uses a large number of carriers spaced apart at slightly different frequencies. In FDMA the corresponding frequency division and allocation will take place and in CDMA and TDMA, code and time division multiplexing will happen accordingly. FDMA (Frequency Division Multiple Access) is a technology by which the total bandwidth available to the system is divided into frequencies. Unlike FDMA, CDMA (Code Division Multiple Access) separates calls by code. Every bit of a conversation is been tagged with a specific and unique code. The system gets a call, it allocates a unique code to that particular conversation, and now the data is split into small parts and is tagged with the unique code given to the conversation of which they are part of. In TDMA (Time Division Multiple Access) the division of calls happens on time basis. The system first digitizes the calls, and then combines those conversations into a unified digital stream on a single radio channel. Now it divides each cellular channel into three time slots that means three calls get put on a single frequency and then, a time slot is assigned to each call during the conversation, a regular space in a digital stream. The users transmit in rapid succession, one after the other, each using its own time slot. This allows multiple stations to share the same transmission medium (e.g. radio frequency channel) while using only a part of its channel capacity. In near future it is expected that the capacity required in a mobile communication network will keep on climbing as the number of mobile stations are increased and apparently the data required in respective mobile stations is increased.

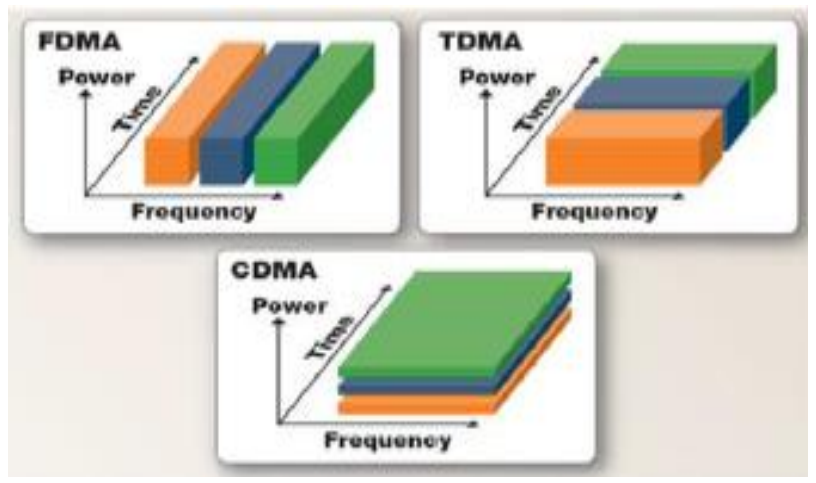

Figure 4: Access Techniques

\section{BDMA}

BDMA refers to Beam Division Multiple Access is the latest allocation technique in which an orthogonal beam is allocated to each mobile station. In this technique, an antenna beam will get divided and allocated into the locations of the mobile stations to provide multiple accesses and thereby increasing the capacity of the system. Since mobile stations and the base stations are in Line of Sight state, they can transmit beams which directed to each other's position for proper communication, without making any kind of interference with cell edge mobile stations. When the mobile stations are positioned at different angles compared to the base station, the base station will transmit the beams in such a way that different angles will be covered and at the same time multiple mobile stations will be taken care. The working is like one mobile station does not use one beam exclusively, but the mobile stations positioned at similar angles will keep on sharing the one beam to communicate with the base station. Mobile stations that are sharing the same beam will divide the same frequency or time resources and will use the orthogonal [1].

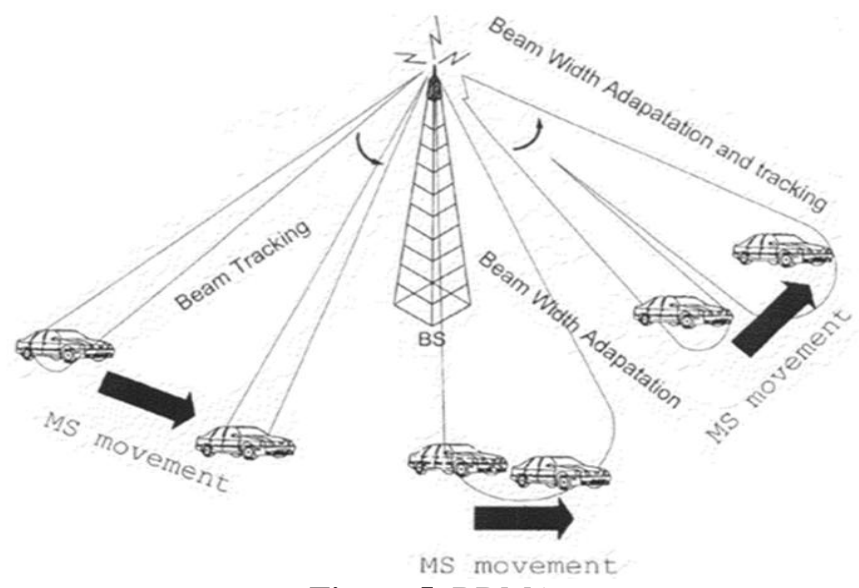

Figure 5: BDMA 


\section{International Journal of Science and Research (IJSR) \\ ISSN (Online): 2319-7064}

Index Copernicus Value (2013): 6.14 | Impact Factor (2014): 5.611

According to the mobile communication environment, a base station can change the direction, number and respective widths of the beams adaptively with the almost easiness. Three dimensional mode of division will happen in the case of beams and hence a spatial reuse of frequency or time resources can be maximized. The first slot of communication is the base station and the mobile station does not know each other's position. The mobile station will detect their positions and the moving speeds and will transmit the entire information to the base station. The second stage is taken care by the base station. The base station will calculate the direction along with the width of a downlink beam which is based on the position and moving speed information received from the mobile station. After the calculation part is over, the base station will transmit the downlink beam to the mobile station with all the calculations regarding the direction and width [4]. $2 \mathrm{Mbps}$ to $100 \mathrm{Mbpa}$

\section{Comparison between $5 \mathrm{G}$ and 4G}

Table 1: Technical Comparison between $5 \mathrm{G}$ and $4 \mathrm{G}$

\begin{tabular}{|c|c|c|}
\hline Specifications & 5G & $4 \mathrm{G}$ \\
\hline $\begin{array}{c}\text { Data } \\
\text { Bandwidth }\end{array}$ & $\begin{array}{c}\text { 1Gbps and higher as peer } \\
\text { need }\end{array}$ & 2Mbps -100Mbps \\
\hline Band & 3 to $300 \mathrm{GHz}$ & 2 to $8 \mathrm{GHz}$ \\
\hline service & $\begin{array}{c}\text { Dynamic information access, } \\
\text { wearable devices, HD } \\
\text { streaming, any demand of } \\
\text { users. }\end{array}$ & $\begin{array}{c}\text { Dynamic } \\
\text { information access, } \\
\text { wearable devices, } \\
\text { HD streaming, } \\
\text { global roaming. }\end{array}$ \\
\hline technologies & $\begin{array}{c}\text { Unified IP, seamless } \\
\text { LANtegration of broadband } \\
\text { advanced technologies based } \\
\text { on OFDM modulation used in } \\
5 \mathrm{G} .\end{array}$ & $\begin{array}{c}\text { Unified IP, } \\
\text { seamless integration } \\
\text { of broadband } \\
\text { LAN/WAN/PAN } \\
\text { and WLAN. }\end{array}$ \\
\hline $\begin{array}{c}\text { Multiple } \\
\text { Access }\end{array}$ & CDMA,BDMA & CDMA \\
\hline Handoff & Horizontal and vertical & $\begin{array}{c}\text { Horizontal and } \\
\text { vertical }\end{array}$ \\
\hline $\begin{array}{c}\text { Initiation } \\
\text { from }\end{array}$ & year-2020 & year-2012 \\
\hline
\end{tabular}

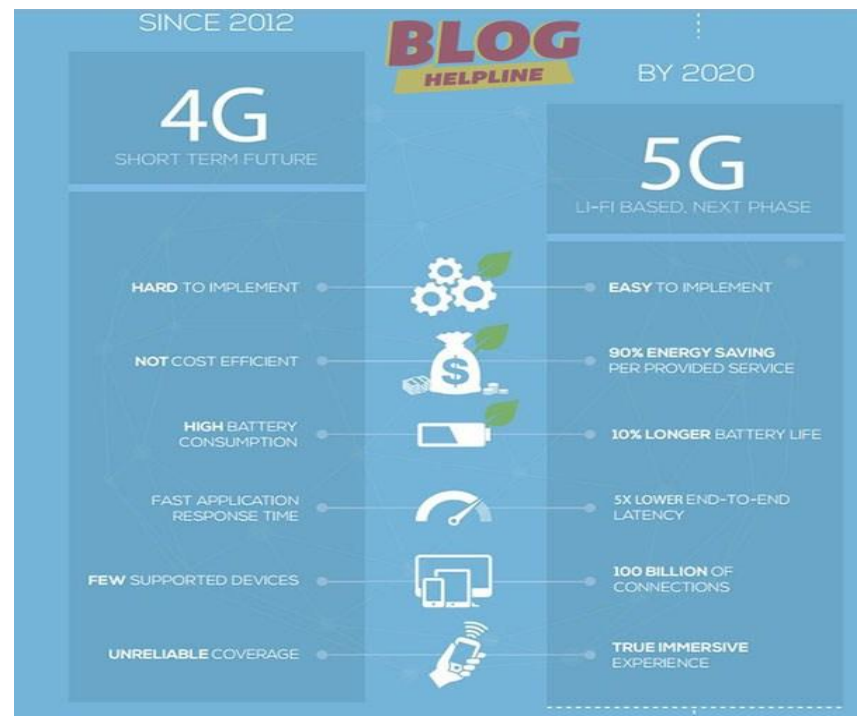

Figure 5: 5G services vs. 4G Services [5].

\section{Conclusion}

The future is becoming more difficult to predict with each passing year but we are on the right road towards the upcoming era, $5 \mathrm{G}$ is made possible by the above explained technologies which includes Nanotechnology, Cloud Computing and all IP Network. This paper tried to help to promote much stronger links between people who will be working and dealing with the very latest future concepts of communication networks, clouding, Internet services and moreover all the functionalities of Nanotechnologies.

\section{References}

[1] Xichun Li, Abdullah Gani, Lina Yang, Omar Zakaria, Badrul Jumaat. "Mix-Bandwidth Data Path Design for 5G Real Wireless World". The Proceeding of WSEAS $13^{\text {th }}$ International Conferences on Multimedia and Communication, Crete Island, Greece, 21- 23, July 2008. pp. 216-221.

[2] Nanotechnology applications to Telecommunications and Networking, by Daniel Minoli, 2005.

[3] Nanotechnologies for Future Mobile Devices by TAPANI RYHA“ NEN Nokia Research Center, Cambridge, 2007.

[4] Imthiyaz Ali.A. 5G The Nano Core. International Journal of Engineering and Innovative Technology (IJEIT), 2(3): 2277-3754, 2012.

[5] http://www.androidauthority.com/4g-and-5g-wirelesshow-they-are-alike-and-how-they-differ-615709/ 